\title{
Personality Characteristics and Anchoring Effect in the Newsvendor Problem: A Laboratory Study
}

\author{
Wenmin Han ${ }^{1, *}$ Min Huang Wenhui Niu \\ ${ }^{1}$ Enter Author Affiliation 1 Jiangsu University of Science and Technology, Zhenjiang, Jiangsu, 212000, China \\ *Corresponding author. Email: $2238344661 @$ qq.com
}

\begin{abstract}
The Ordering decisions made by decision-makers are affected by their personality characteristics and uncertain market environment, and have always been focused on by scholars. This study used MBTI to classify the personality characteristics of decision-makers, and the E-prime software combined with the newsvendor model is used to simulate the ordering process of decision-makers. The experimental data are subjected to GMM regression analysis to explore the influence of the decision-maker's personality characteristics on the ordering decision. The results show that the previous market demand has a significant impact on decision-makers in the uncertain market environment, indicating that participants have a significant anchoring effect. The order quantity of extroverted participants higher than that of introverted participants. With the increase of trials, the order quantity of the decision-maker has the obvious pull-tocenter effect and stabilizes at a subjective level.
\end{abstract}

Keywords: newsvendor model, MBTI, order decision, anchoring effect, experiment.

\section{INTRODUCTION}

In the face of uncertain market demand, ordering decision as one of the important links of enterprise production operation management, has a direct impact on the operating profit of the enterprise. The decisionmaker is the maker of the order plan, and the order decision process is affected by many factors, such as the external environment, the personality characteristics of the decision-maker, risk preference, fairness preference, experience. Personality characteristics are important factors that affect personal attitudes and risk judgments. Especially in an uncertain market environment, the impact of different decision-makers' personality characteristics on ordering decisions has been widely concerned.

In view of the research on the impact of decisionmaker's personality characteristics on decision-making, most scholars have adopted the newsvendor model as an effective decision-making model for makers in an uncertain market demand environment. Some studies have found that decision-makers tend to fix their orders near the average demand, and people tend to give greater weight to the information they have obtained when making decisions. This is called the "anchor effect". Schweitzer and Cachon study shows that the order quantity of participants deviated systematically from the order quantity with the maximum expected utility and had a tendency to approach the mean demand, which was called "pull-to-center effect" [16]. However, Siegel study shows that when the demand presents an exponential distribution or a normal distribution [17]. The expected estimated deviation of the order quantity is 0 . Wu D et al. believe that the overconfident decisionmaker thinks his own decisions are more accurate, and the conservatism caused by loss aversion will be mitigated to some extent by overconfident decisionmakers [21]. However, personality characteristics make the order quantity expectations deviate from the order quantity with the maximum expected utility.

Scholars such as Bostian, Benzion et al. have conducted experiments on the newsvendor problem by changing the experimental environment and different analytical perspectives $[1,2,3]$, and they have found that the newsvendor model has a pull-to-center effect to different degrees. Benzion believes that the order quantity is also affected by the average demand and the optimal order quantity [1]. Camerer, C. F et al. introduced empirical factors into the newsvendor model to improve the accuracy of prediction $[4,7,11]$, and the anchoring effect plays an important role in decisionmaking [22]. 
In response to this problem, many scholars have introduced the difference of decision-maker's personality characteristics into the newsvendor model as a disturbance factor. Long $\mathrm{X}$ and Nasiry et al. proposed a newsvendor model with heterogeneous reference points for decision-makers based on prospect theory $[6,14]$, and found that personal characteristics will greatly affect ordering decisions. Feng T, Juanchich M and other studies have found that personality characteristics has a higher utility in predicting decisionmaking $[5,8,10,12,15]$. In terms of the personality characteristics of decision-makers, Freund and Welsh MB believe that MBTI can effectively identify the personality characteristics types of decision-makers $[9,20]$.

In summary, both personality characteristics and anchoring effects affect the results of the ordering decision, which deviates from the optimal ordering decision and has a pulling-to-center effect to varying degrees. This study takes different personality characteristics as variables to explore the decisionmaking biases in one scenario, and whether the deviations have trends. Firstly, the MBTI scale is introduced on this basis, and the market demand is configured on following the normal distribution for simulating the actual market environment. Secondly, through a fixed method of obtaining information, a continuous ordering decision-making simulation experiment is performed on participants with different personality characteristics. Panel data combines individual and time trends, which could analyze and predicts the explained variables through each explanatory variable. Depending on the data, a dynamic panel model was constructed and the GMM system regression value was estimated.

\section{EXPERIMENTAL PROCEDURE}

\section{1 participants}

This study recruited 30 healthy, right-handed graduate students majoring in engineering and management $(19$ females, mean age $=23.5$ years, range 22 - 27), participants had normal vision or corrected normal vision. Participants have not participated in similar experiments. Before the experiment, participants were asked to get enough sleep. No alcohol, stimulant drinks such as tea or coffee, and no drugs were allowed for 24 hours before the experiment. At the end of the experiment, participants were rewarded according to their results.

\subsection{Experimental design}

In order to classify different decision-makers, this study uses the MBTI personality scale to classify the participants before the experiment. At the same time, in order to simulate the ordering decision-making process of the decision-maker under uncertain environment. This study takes the last 5 years of monthly sales quantity of actual enterprise as the market demand, and converts it into a normal distribution with $\mu=150$. There are 60 trials rounds in 2 rounds, and each trial is independent of each other. Under the scenario setting, the unit profit of the product is 6 units. If you produce one more product, you will lose 6 units of sunk cost, and the salvage value 0 . Conversely, if you produce one less product, you will lose 6 units opportunity costs. Before the start of the first round, the market demand of the last 10 periods will be displayed as a line graph. Participants have 30 s to scrutinize the data and observe trends in order to predict the market demand in the next trial. Participants need to make decisions consistent with the market demand as much as possible, so as to maximize the returns of each round and the total returns. Fig 1 shows the process.

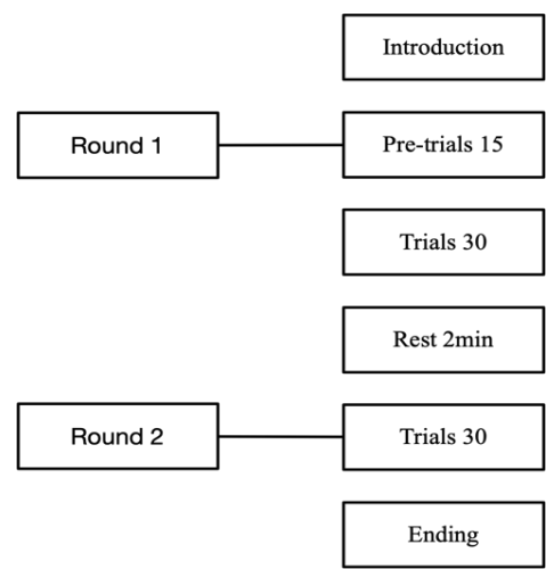

Figure 1 Experimental process design.

\section{RESULTS}

\subsection{Data analysis}

Assume that participants do not take into consideration the impact of historical demand on decision-making behaviors, participants will anchor the market demand at about 150. Figure 2 shows the order quantity of introverted participants and extroverted participants. The difference in the order quantity is small, indicating the possible anchoring effect. Table 1 shows the order quantity of extroverted participants and introverted participants are significantly different with the increase of trials, $\mathrm{p}=0.013$ in Round 2. The order quantity of extroverted participants was significantly higher than that of introverted participants. In the other three dimensions, there is no significant difference in order quantity. The order quantity of each dimension is $[140,160]$, which is near the mean value and indicating the possible pull-to-center effect. Next, building a decision model to verify its possibility. 
Table1.Extrovert and Introvert Paired sample T test

\begin{tabular}{|c|c|c|c|c|c|c|c|}
\hline & group & Mean & Std. Dev & Std. Err. & \multicolumn{2}{|c|}{$95 \%$ Conf.Interval } & sig \\
\hline \multirow{2}{*}{ Round 1} & Extrovert & 162.654 & \multirow{2}{*}{3.221} & \multirow{2}{*}{3.107} & \multirow{2}{*}{-3.143} & \multirow{2}{*}{9.586} & \multirow{2}{*}{0.309} \\
\hline & Introvert & 159.433 & & & & & \\
\hline \multirow{2}{*}{ Round 2} & Extrovert & 153.788 & \multirow{2}{*}{8.274} & \multirow{2}{*}{3} & \multirow{2}{*}{1.919} & \multirow{2}{*}{14.627} & \multirow{2}{*}{0.013} \\
\hline & Introvert & 145.515 & & & & & \\
\hline
\end{tabular}

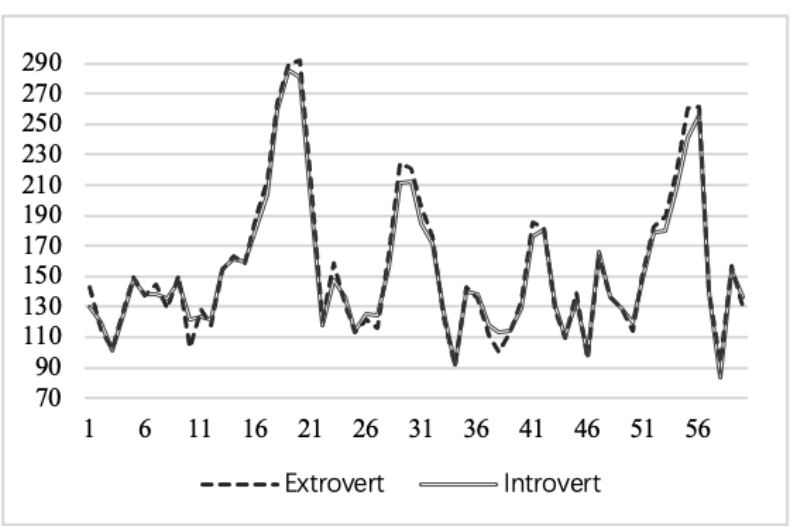

Figure 2 Ordering quantity of Extrovert group and Introvert group.

\subsection{Model Analysis}

Based on anchoring theory and pull-to-center effect proposed by Schweitzer, this study constructs the dynamic panel model and analyses the order quantity of different personalities and estimates the correlation coefficient. Not only the newsvendor affected by the degree of difference, but also affected by other factors. According to the previous study, the prediction model constructed as following:

$q_{i, t}=q_{i, t 1}+d_{t 1}+v_{i}+{ }_{i, t}$

$q_{i, t}$ is the order quantity in trial; $d_{t-1}$ is the market demanded in t-1 trial. $v_{i}+\varepsilon_{i, t}$ form the perturbation terms, and $v_{i}$ is a dummy variable reflecting the individual effect of decision making. $\varepsilon_{i, t}$ is a random perturbation term that varies with individuals and time. The pre-order quantity $q_{t-1}$ and the demand $d_{i, t-1}$ could as the weighted value for the next trial of decision quantity. $\beta$ mean that newsvendor anchor weight. $\alpha$ means that newsvendor adjust weight. $\alpha$ increase means less change in decision quantity, and close to a subjective ordering level. $\beta$ increase means anchoring effect.

According to the cross-sectional correlation test, we found that the error term of the model has autocorrelation, heteroscedasticity and cross-sectional correlation. Through the Hausman test, $\mathrm{P}$ value is 0 , less than 0.1 , and the measured variable is considered to be an endogenous variable. $\operatorname{AR}(1)$ value $p=0.016$,. $\operatorname{AR}(2)$ value $\mathrm{p}=0.561$. This indicates that there is a first-order autocorrelation, but no second-order autocorrelation. The utility variable has autocorrelation. Hansen value $\mathrm{p}=1$, utility variable has validity.

From the parameter estimation results in Table 2, it can be seen that $\alpha$ is obviously positive for one phase lag. $\beta$ fluctuates between $[0.7,1]$ indicating that there have a significant anchoring effect, the decision-maker anchors the previous market demand. $\alpha$ fluctuates between $[0,0.3]$, which shows that the decision-maker is a dynamic adjustment process in the decision-making process. Table 2 shows the GMM system panel data. The intuition group $\alpha$ value is not between OLS and LSDV, which indicating it is not valid. The increase of $\alpha$ and the decrease of $\beta$ indicate that the decision-maker has a subjective level of order quantity. And most personality will adjust the subjective order according to the information. The adjustment coefficient $\alpha$ of perceptual participants changed from positive to negative in the two rounds, indicating that perceptual group significantly anchored the previous demand and were more depended on data. According to the average order quantity of participants and the mean value of 150 , a single sample $\mathrm{T}$-test was performed $\mathrm{p}=0.716$ and there is no significant difference, indicating that the participant's decision has a significant pull-to-center effect.

Table 2. GMM regression results

\begin{tabular}{|c|c|c|c|c|c|c|c|c|c|}
\hline \multirow{2}{*}{ group } & & \multirow{2}{*}{$\frac{\text { OLS }}{\alpha}$} & \multirow{2}{*}{$\begin{array}{c}\text { LSDV } \\
\alpha\end{array}$} & \multicolumn{2}{|c|}{ GMM } & \multirow{2}{*}{$\operatorname{AR}(1)$} & \multirow{2}{*}{$\operatorname{AR}(2)$} & \multirow{2}{*}{ hansen } & \multirow{2}{*}{ wald } \\
\hline & & & & $\alpha$ & $\beta$ & & & & \\
\hline \multirow{2}{*}{ Judging } & Round1 & 0.2049 & 0.06698 & 0.1475 & 0.828 & 0.002 & 0.254 & 1 & 0 \\
\hline & Round2 & 0.3279 & 0.1609 & 0.2842 & 0.791 & 0.023 & 0.248 & 1 & 0.0001 \\
\hline \multirow[t]{2}{*}{ Perceiving } & Round1 & 0.2633 & 0.1903 & 0.2281 & 0.748 & 0.003 & 0.404 & 1 & 0.0255 \\
\hline & Round2 & 0.0267 & -0.104 & -0.018 & 0.838 & 0.005 & 0.614 & 1 & 0 \\
\hline \multirow{2}{*}{ Extrovert } & Round1 & 0.3666 & 0.0946 & 0.2267 & 0.0008 & 0.009 & 0.894 & 1 & 0.0171 \\
\hline & Round2 & 0.2906 & 0.0186 & 0.2217 & 0.9194 & 0.069 & 0.709 & 1 & 0 \\
\hline \multirow{2}{*}{ Introvert } & Round1 & 0.182 & 0.094 & 0.1676 & 0.81 & 0.002 & 0.233 & 1 & 0 \\
\hline & Round2 & 0.2185 & 0.1377 & 0.1912 & 0.694 & 0.001 & 0.22 & 1 & 0.0017 \\
\hline \multirow{2}{*}{ Sensing } & Round1 & 0.2361 & 0.1119 & 0.1915 & 0.7373 & 0 & 0.672 & 1 & 0 \\
\hline & Round2 & 0.291 & 0.1126 & 0.2405 & 0.7665 & 0.014 & 0.435 & 1 & 0 \\
\hline
\end{tabular}




\begin{tabular}{|c|l|c|c|c|c|c|c|c|c|}
\hline \multirow{2}{*}{ iNtuition } & Round1 & 0.291 & 0.0762 & -0.0001 & 0.996 & 0.022 & 0.171 & 1 & 0.0022 \\
\cline { 2 - 10 } & Round2 & 0.112 & 0.0152 & 0.101 & 0.8542 & 0.014 & 0.937 & 1 & 0.0001 \\
\hline \multirow{2}{*}{ Feeling } & Round1 & 0.2415 & 0.0712 & 0.081 & 0.9074 & 0.002 & 0.116 & 1 & 0.0013 \\
\cline { 2 - 10 } & Round2 & 0.2123 & -0.0035 & 0.1056 & 0.837 & 0.001 & 0.909 & 1 & 0.0002 \\
\hline \multirow{2}{*}{ Thinking } & Round1 & 0.2123 & 0.1028 & 0.1659 & 0.7825 & 0.004 & 0.675 & 1 & 0 \\
\cline { 2 - 9 } & Round2 & 0.3026 & 0.1473 & 0.2777 & 0.7068 & 0.062 & 0.606 & 1 & 0.0043 \\
\hline
\end{tabular}

\section{DISCUSSION AND CONCLUSION}

This research analyzes the ordering decision problems of participants with different personality characteristics in laboratory. The results show, first, the ordering decision of the decision-maker has a significant correlation with the previous market demand, and has strong anchoring effect. Second, the anchoring coefficient and the adjustment coefficient are significantly positive, and it is a dynamic adjustment process. Third, from a long-term perspective, participants have an obvious pull-to-center effect when making ordering decisions.

The adjustment coefficient indicates that the participants have a process of understanding and strengthening the cognition of information, and in the end will form a knowledge and rules that can guide decision-making [13]. The anchoring coefficient and the adjustment coefficient are different in the two rounds, indicating that it is a dynamic adjustment process. Although the decision-making process should be dependent on past experience, the external environment is constantly changing. The decision-maker must grasp the key points of the previous decision-making and analyze the fixed and changing conditions of the market environment. In addition, decision-makers must make judgments on existing external information and accurately obtain external valid information, so as to reduce invalid costs and increase benefits in an uncertain market environment. In fact, some scholars have considered the shortcomings of the newsvendor model and incorporated various factors like profit risk constraints into the model. However, these analyses are based on theory, and further research should study how personality characteristics affect decision-making for increasing the practical application value.

\section{REFERENCES}

[1] Benzion U, Cohen Y, Peled R, Shavit T. Decision-making and the newsvendor problem - an experimental study[J]. Journal of the Operational Research Society, 2008, 59(9):1281-1287.

[2] Bolton G E, Katok E. Learning by doing in the newsvendor problem: A laboratory investigation of the role of experience and feedback [J]. M\&SomManufacturing \& Service Operations Management, 2008, 10: 519-538.
[3] Bostian A A, Holt C A, Smith A M. Newsvendor "pull-to-center" effect: adaptive learning in a laboratory experiment $[\mathrm{J}]$. Manufacturing \& Service Operations Management, 2008, 10(4): 590-608.

[4] Camerer, C. F., C.. Anderson. 2000. Experienceweighted attraction learning in sender-receiver signaling games. Econom. Theory 16 689-718.

[5] Dewberry C , Juanchich M , Narendran S . Decision-making competence in everyday life: The roles of general cognitive styles, decision-making styles and personality[J]. Personality \& Individual Differences, 2013, 55(7):783-788.

[6] Eeckhoudt L, Gollier C, H S 1995. The risk-averse (and prudent) newsboy. Management Science [J], 41(5): 786-794.

[7] Fellner, G., M. Sutter. 2008. Causes, consequences, and cures of myopic loss aversion-An experimental investigation. Econom. J. Forthcoming.

[8] Feng T , Keller L R , Zheng X . Decision making in the newsvendor problem: A cross-national laboratory study[J]. Omega, 2011, 39(1):41-50.

[9] Freund, Cynthia, M. Decision-Making StylesManagerial Application of the MBTI and Type Theory[J]. Jona the Journal of Nursing Administration, 1989.

[10] Gosling S D , Rentfrow P J , Swann W B . A very brief measure of the Big-Five personality domains[J]. Journal of Research in Personality, 2003, 37( 6):504-528.

[11] Ho, T.-H., C. F. Camerer, J.-K. Chong. 2007. Selftuning experience weighted attraction learning in games. J. Econom. Theory 133 177-198.

[12] Juanchich M , Dewberry C , Sirota M , et al. Cognitive reflection predicts real-life decision outcomes, but not over and above personality and decision-making styles[J]. Journal of Behavioral Decision Making, 2016, 29(1).

[13] Jian H , Wang G , Minli X U , et al. A Laboratory Study of Decision Making and Behavior Analysis in "Newsvendor Problem". Journal of Beijing Institute of Technology(Social Sciences Edition), 2014. 
[14] Long X , Nasiry J . Prospect Theory Explains Newsvendor Behavior: The Role of Reference Points[J]. Management Science, 2014, 61(12): 3009-3012.

[15] Ming-Hong, Tsai, Nadhilla, et al. The Effects of Perceived Decision-Making Styles on Evaluations of Openness and Competence That Elicit Collaboration.[J]. Personality \& Social Psychology Bulletin, 2019.

[16] Schweitzer M E , Gérard P. Cachon. Decision Bias in the Newsvendor Problem with a Known Demand Distribution: Experimental Evidence[J]. Management ence, 2000, 46(3):404-420.

[17] Siegel Andrew F., Wagner Michael R.. Profit Estimation Error in the Newsvendor Model Under a Parametric Demand Distribution. 2020, 10.1287/MNSC.2020.3766

[18] Uppari B S , Hasija S . Modeling Newsvendor Behavior: A Prospect Theory Approach[J].
Manufacturing and service operations management, 2019, 21(3):481-500.

[19] Wei Liu, Shiji Song, Ying Qiao, et al. The LossAverse Newsvendor Problem with Random Yield and Reference Dependence[J]. Mathematics, 2020, $8(8)$

[20] Welsh M B , Alhakim A , Ball F, et al. Do personality traits affect decision-making ability: can MBTI type predict biases?[J]. Appea Journal, 51.

[21] Wu D , Chen F . The overconfident and ambiguityaverse newsvendor problem in perishable product decision[J]. Computers \& Industrial Engineering, 2020, 148:106689.

[22] Wu M , Bai T, Zhu S X . A loss averse competitive newsvendor problem with anchoring[J]. Omega, 2018:S0305048317303560.J. Clerk Maxwell, A Treatise on Electricity and Magnetism, 3rd ed., vol. 2. Oxford: Clarendon, 1892, pp.68-73. 